\title{
TREND OF CONGENITAL ANOMALIES IN ALBANIA
}

\section{Ilirjana Bakalli, Elmira Kola, Robert Lluka, Ermela Celaj, Durim Sala, Inva Gjeta, Sashenka Sallabanda Pediatric Intensive Care Unit, University Hospital Center "Mother}

\section{Introduction}

Congenital anomalies (CA) are an important cause of death, but also of long term handicaps with significant effect on society.

We aimed to evaluate the prenatal diagnosis, the trend of CA, mortality rate and factors affecting their prognosis.

\section{Methods:}

We enrolled in our study all children with CA who underwent surgery during January 2007December 2016. We compared prenatal diagnosis, incidence and mortality for the two five-year periods: $1^{\text {st }}$ period $(2007-2011), 2^{\text {nd }}$ period (2012-2016). Children with congenital cardiac and neurological anomalies are excluded from the study. Data for live births in Albania have been obtained from the National Register of the Institute of Statistics.

\section{Results}

During the study period, a total of 323 cases with CA were presented with an incidence of 0.69-1.11 per 1000 live births. Comparing the two periods for the incidence we didn't find statistical differences $(\mathrm{P}=0.132)$, but the mortality rate has been reduced from $34 \%$ during the $1^{\text {st }}$ period to $25.3 \%$ during the $2^{\text {nd }}$ period $(\mathrm{P}=0.08)$. Prenatal diagnosis has increased: $28 \%$ in the $2^{\text {nd }}$ period compared with $10 \%$ in the $1^{\text {st }}$ period $(\mathrm{P}<0.001)$, but without affecting significantly the prognosis. (AUC $=0.558$, $\mathrm{P}=0.09$ ).

\begin{tabular}{|l|c|c|c|c|c|c|c|c|c|c|}
\hline & 2007 & 2008 & 2009 & 2010 & 2011 & 2012 & 2013 & 2014 & 2015 & 2016 \\
\hline Admissions & 576 & 596 & 560 & 615 & 478 & 620 & 718 & 654 & 592 & 757 \\
\hline Anomalies & 36 & 28 & 24 & 37 & 28 & 42 & 38 & 40 & 28 & 22 \\
\hline Incidence & 1.04 & 0.83 & 0.7 & 1.08 & 0.81 & 1.18 & 1.06 & 1.11 & 0,85 & 0.69 \\
\hline
\end{tabular}

Premature babies' birth resulted a significant negative predictive factor for the prognosis of these abnormalities. (AUC=0.620, $\mathrm{P}<0.0001$ ). Birth in a secondary center also didn't affect significantly the negative prognosis $(\mathrm{P}=0.19)$.

\section{Conclusion}

Prenatal diagnosis is increasing recently; even though remain low in our country. Advances made in recent years in intensive care, surgical techniques and parenteral nutrition have significantly increased the survival of neonates born with CA.

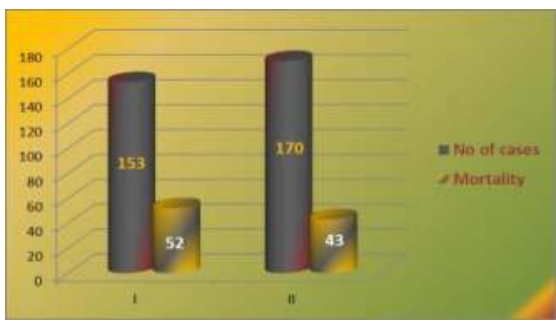

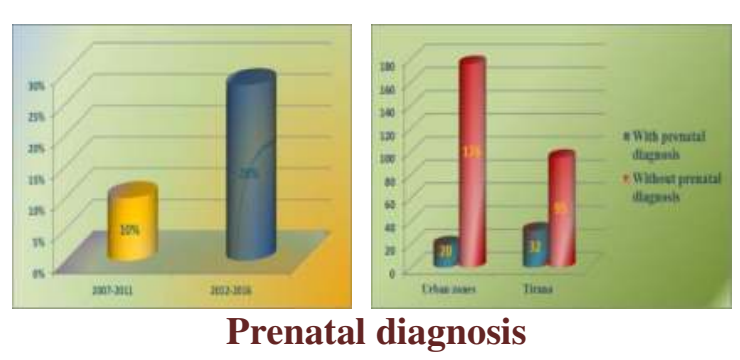

Prenatal diagnosis

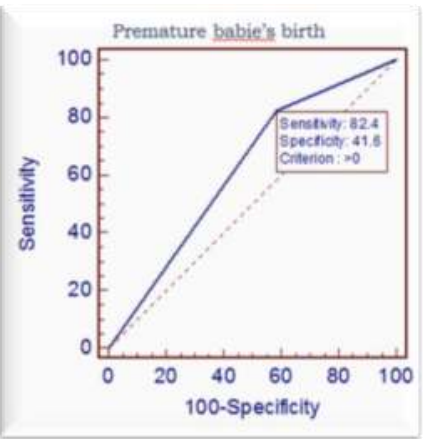

